\title{
Climate change and agricultural adaptation: assessing management uncertainty for four crop types in Spain
}

\author{
Ana Iglesias ${ }^{1, *}$, Sonia Quiroga ${ }^{2}$, Jeremy Schlickenrieder ${ }^{1}$ \\ ${ }^{1}$ Department of Agricultural Economics and Social Sciences, Universidad Politécnica de Madrid, 28040 Madrid, Spain \\ ${ }^{2}$ Department of Statistics, Economic Structure and International Organisation, Universidad de Alcalá, \\ 28802 Alcalá de Henares, Madrid, Spain
}

\begin{abstract}
Climate change inevitably leads to large regional variations in risks and opportunities and is likely to affect most farmers in the Mediterranean in the next decades. The interpretation of climate projections to determine appropriate policy responses is not without difficulties, such as understanding local uncertainty and responses of specific crops to sets of conditions. Here we analyse the potential impacts of climate on agriculture in the Mediterranean - a region that exemplifies other regions of the world that are prone to drought and are likely to experience increased frequency and intensity of droughts in the future. Our analysis relies on understanding the sources of uncertainty derived from climate scenarios, agricultural systems, impact responses and risk levels to support informed decisions for planned agricultural adaptation. We generated multiple projections of impacts based on different models of climate change and crop response in order to capture uncertainties. We used statistical models of yield response and projections of climate change generated from 16 climate scenarios to address the likelihood of projected impacts on traditional Mediterranean farming systems, represented in this study by cereals, grapes, olives and citrus. Results show that uncertainty varies widely by crop and location, and adaptation priorities will therefore depend on the risk focus of adaptation plans.
\end{abstract}

KEY WORDS: Uncertainty $\cdot$ Climate change $\cdot$ Risk $\cdot$ Adaptation $\cdot$ Agriculture $\cdot$ Mediterranean region

\section{INTRODUCTION}

Anticipating the potential impacts of climate change and their likelihood are the main considerations in developing mitigation and adaptation policies. Impacts and likelihood are determined by a wide range of assumptions about future society, the choice of climate model, the analytical tools used and data (Fronzek \& Carter 2007). Many argue that it is possible to reduce uncertainty by making clear assumptions (Hulme et al. 1999). However, future projections are inherently uncertain and, therefore, even the application of scientific rigor will not completely eliminate this aspect of the projections; therefore, uncertainty must be ad- dressed. Characterisation of uncertainty is difficult owing to its multiple determinants and local system specificity. Understanding the impact and likelihood of climate change is complicated owing to inconsistencies of inputs across geographic and time scales and changes in physical and social variables that are often derived from different assumptions. As result, some of the more profound or severe consequences of climate change may be more difficult to project than the future climate itself. In this paper we address some of these challenges.

Climate change will have a differential effect on regional agriculture owing to the disparity in the baseline conditions and the magnitude of change expected 
(Saarikko \& Carter 1996). In some agricultural areas, farmers will be less able to cope with the changes, whereas others may even benefit; ensuring an optimal level of adaptation requires consistent information on regional and local disparities (Commission of the European Communities 2009), as well as the implementation of adequate agricultural programs and policies.

Here we focus on agriculture in the Mediterranean, a well-studied region from the climate and agricultural points of view (Olesen \& Bindi 2002, Iglesias et al. 2007, IPCC 2007, European Environment Agency 2008, Giorgi \& Lionello 2008). The Mediterranean region comprises the world's largest area of olives, grapes and citrus, as well as extensive cereal production. These 4 crops make up $>30 \%$ of Spanish agricultural area (Table 1), and they are often considered to represent the typical Mediterranean crops, excluding cereals and some fruits (FAO 2010). The rest of the crops that represent a large proportion of the crop area (i.e. maize, sunflower, rice and potatoes) are not exclusively considered Mediterranean. The four crops studied form an important part of the history and diet of the region, and their future will partially determine the socio-economic and environmental development of many rural areas.

Adaptation is a key factor that will determine the future severity of climate change impacts on agriculture and food production (Brooks et al. 2005, Burton and Lim 2005, Howden et al. 2007, Lobell et al. 2008). Prioritizing climate change policies in the agricultural sector requires information on: (1) assumptions about the future climate, (2) characterisation of regional disparities and local realities, and (3) sources of uncertainty in the assessment. Here we characterise impacts and likelihood by addressing the uncertainty of the scenario in question and the local conditions (location and type of agricultural system), and the evaluation of probabilistic impacts.

Table 1. Cultivation of olives, citrus, cereals and grapes in Spain and the Mediterranean (FAO 2010)

\begin{tabular}{|lcc|}
\hline & $\begin{array}{c}\text { Area in Spain } \\
\left(10^{6} \text { ha }\right)\end{array}$ & $\begin{array}{c}\text { \% of all Mediterranean } \\
\text { countries (in Europe } \\
\text { and North Africa })\end{array}$ \\
\hline Total agricultural & 27.9 & 13 \\
$\quad$ area & 6.0 & 13 \\
Cereals & 1.1 & 30 \\
Grapes & 2.5 & 27 \\
Olives & 0.3 & 27 \\
Citrus & 9.9 & 17 \\
Total 4 crops & $35 \%$ & \\
Proportion of total & & \\
agricultural area & & \\
\hline
\end{tabular}

\section{METHODS}

\subsection{Approach}

Uncertainties in projections of crop production were recognised early in the 1990s and are derived from climate-change projections, scenarios and other factors (Carter et al. 1991). Our analysis relies on understanding the sources of uncertainty derived from climate scenarios, agricultural systems, impact responses and risk level to support informed decisions for planned adaptation. We generate multiple projections of impacts based on different models of climate change and crop response in order to capture uncertainties. The study includes 4 components (Fig. 1): (1) A multiscenario framework addresses the climate uncertainty. (2) Range of crop choices and contrasting locations addresses the uncertainty derived from the agricultural system. (3) The probabilistic risk level is derived from Monte Carlo analysis. (4) We derive an impact to risk index that allows comparison of uncertainty across regions and crops in the evaluation of informed decisions. The study sites are located in the Mediterranean region (Spain), exemplifying other drought-prone and water-scarce areas that are likely to experience drought intensification in the future. The crops selected are the major crops in the region: cereals, citrus, grapes and olives.

Our methodology incorporates a number of strengths: it is based on the evaluation of crop responses of 4 different crops that have future social and environmental implications, and uses a range of emissions scenarios to provide insights into the effects of climate-change policy. The risk approach expands impact results and

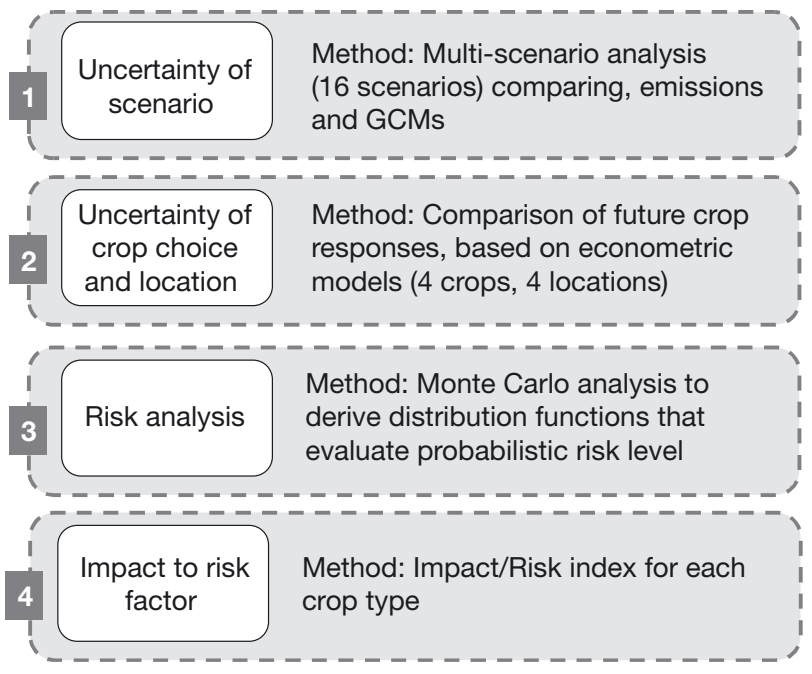

Fig. 1. A framework for analysing uncertainty to support informed decisions. GCM: global climate model 
therefore addresses the important issue of likelihood. The methodology addresses some uncertainty questions relevant for policy development in the region (Table 2). The present study does not, however, deal with some important sources of uncertainty, including those derived from increases of food demand, both in quantity and as a result of changing lifestyles and diet, which add an additional layer of complexity to predictions of how climate change may affect crop production (Long et al. 2006).

\subsection{Climate-change scenarios}

In the Fourth Assessment Report (AR4), the IPCC discussed improved models that enabled better estimates of climate change for different emissions scenarios (IPCC 2007). These projections of future climate change from numerical models have existed for some time, but the PRUDENCE project has provided highresolution climate change scenarios for Europe for the end of the 21st century (Fronzek \& Carter 2007). This modelling process involved 3 steps. (1) The Special Report on Emissions Scenarios (SRES) provides projections of atmospheric greenhouse gas emissions as a result of changes in population, economic activities and environmental policy (IPCC 2000). (2) The greenhouse gas concentration is then used in the global climate models (GCMs) to compute resulting global climate variables as result of this climate forcing. There are a range of GCMs and their resolution varies, but none of the actual GCMs have a resolution smaller than $1^{\circ}$ latitude by $1^{\circ}$ longitude. (3) To increase resolution, the output from the GCMs can be downscaled by regional climate models (RCMs); this is called dynamical downscaling. The PESETA project (Ciscar et al. 2009) used the PRUDENCE output to project climatechange scenarios at the site level for its agricultural analysis. There are alternative downscaling techniques to produce high-resolution projections. Statistical downscaling is based on observed local climate properties. Stochastic weather generators are models which use observed weather local data to simulate synthetic time-series of daily weather that are statistically similar to observed weather in the desired local site. Semenov \& Stratonovitch (2010) have recently released a weather generator which includes the predictions from different GCMs used in the IPCC AR4 and generates a multi-model ensemble.

Climate change is characterised from a range of global change scenarios. Since no single projection is a prediction, scenarios represent alternative futures. Scenarios of future climate are constructed based on 2 steps. (1) Future greenhouse gas emissions are defined as a result of future social and economic conditions: population levels, economic growth and energy policy, among others. The socio-economic futures are defined by the SRES scenarios (IPCC 2000). (2) GCMs that represent atmospheric physics and energy flows are forced by the future concentration of greenhouse gases, resulting in altered climatic variables. Here we used 16 climate-change scenarios that allow for comparison between socio-economic drivers of greenhouse gas emissions (derived from the 4 SRES scenarios) and 4 GCMs, for the period 2071 to 2100 (Table 3). The source of the data is the IPCC Data Distribution Centre (DDC) and the Tyndall Centre (Mitchell et al. 2004).

The IPCC SRES (IPCC 2000) represent potential socio-economic futures that determine the level of greenhouse gas emissions to the atmosphere. Each socio-economic scenario provides a description of possible future developments. Here we considered SRES of the A and B families, since they are widely applied and cover a broad range of possible population growth and economic development. The A scenarios represent a vision of the future where economic development is the priority, whereas the B scenarios represent a future where environmental sustainability plays a central role. Although A1 and B1 scenarios are based on a more integrated world in terms of its development approach, A2 and B2 scenarios represent a world that is more divided in this regard.

Table 2. Uncertainty questions, methodological approach and policy implications to address decisions regarding adaptation to climate change

\begin{tabular}{|lll|}
\hline Uncertainty question & Methodological approach & Policy implications \\
\hline $\begin{array}{l}\text { Are there differential risks to crop } \\
\text { production arising from different } \\
\text { socio-economic and climate scenarios? }\end{array}$ & Multi-scenario approach & $\begin{array}{l}\text { Boundaries of possible futures; } \\
\text { benefits of mitigation action }\end{array}$ \\
$\begin{array}{l}\text { How do location and crop type affect } \\
\text { uncertainty of projected impacts? }\end{array}$ & Regional and crop analysis & $\begin{array}{l}\text { Choice of crop and diversification of farming } \\
\text { system }\end{array}$ \\
$\begin{array}{l}\text { What risks are farmers willing to } \\
\text { accept? }\end{array}$ & $\begin{array}{l}\text { Monte Carlo probabilistic analysis; } \\
\text { risk factor }\end{array}$ & $\begin{array}{l}\text { Selection of threshold levels for insurance pro- } \\
\text { tection to extreme events; define risk attitude }\end{array}$ \\
\hline
\end{tabular}


Table 3. Summary of the 16 climate scenarios used in the study. Source of data: IPCC Data Distribution Centre and Tyndall Centre (Mitchell et al. 2004). Precipitation and temperature change: mean error over Spain between the present and 2071-2100. SRES: Special Report on Emissions Scenarios

\begin{tabular}{|lccccc|}
\hline \multirow{2}{*}{ Scenario } & \multirow{2}{*}{ Model } & $\begin{array}{c}\text { Spatial } \\
\text { resolution }\end{array}$ & $\begin{array}{c}\text { Driving } \\
\text { socio-economic } \\
\text { scenario (SRES) }\end{array}$ & $\begin{array}{c}\text { Precipitation } \\
\text { change } \\
\left(\mathrm{mm} \mathrm{d}^{-1}\right)\end{array}$ & $\begin{array}{c}\text { Temperature } \\
\text { change } \\
\left({ }^{\circ} \mathrm{C}\right)\end{array}$ \\
\hline 1 & & & & & \\
2 & CGCM2A1 & $3.75^{\circ} \times 3.75^{\circ}$ & $\mathrm{A} 1$ & -0.3033 & 4.7 \\
3 & CGCM2A2 & & $\mathrm{A} 2$ & -0.2447 & 3.8 \\
4 & CGCM2B1 & & $\mathrm{B} 1$ & -0.0732 & 2.1 \\
5 & CGCM2B2 & & $\mathrm{B} 2$ & -0.0893 & 2.5 \\
6 & CSIRO2A1 & $3.2^{\circ} \times 5.6^{\circ}$ & $\mathrm{A} 1$ & 0.0263 & 3.7 \\
7 & CSIRO2A2 & & $\mathrm{A} 2$ & -0.0912 & 3.9 \\
8 & CSIRO2B1 & & $\mathrm{B} 1$ & -0.0315 & 2.9 \\
9 & CSIRO2B2 & & $\mathrm{B} 2$ & -0.0400 & 3.1 \\
10 & HadCM3A1 & $2.5^{\circ} \times 3.75^{\circ}$ & $\mathrm{A} 1$ & -0.4268 & 5.8 \\
11 & HadCM3A2 & & $\mathrm{A} 2$ & -0.3773 & 4.4 \\
12 & HadCM3B1 & & $\mathrm{B} 1$ & -0.3287 & 2.9 \\
13 & HadCM3B2 & & $\mathrm{B} 2$ & -0.1712 & 3.3 \\
14 & PCMA1 & $2.8^{\circ} \times 2.8^{\circ}$ & $\mathrm{A} 1$ & -0.1890 & 3.1 \\
15 & PCMA2 & & $\mathrm{A} 2$ & -0.1537 & 2.5 \\
16 & PCMB1 & & $\mathrm{B} 1$ & -0.1208 & 1.5 \\
& PCMB2 & & $\mathrm{B} 2$ & -0.1490 & 1.9 \\
\hline
\end{tabular}

\subsection{Crops and agricultural models}

To understand the components of yield variability in a range of agro-climatic conditions, we used econometric models of yield response with climatic data as explanatory variables (Iglesias \& Quiroga 2007, Quiroga \& Iglesias 2009). The models also consider the effect of technical progress, incorporating several management indicators as input variables. Technological change, represented by farm machinery and fertiliser application, results in yield increases for all crops, whereas irrigation is the main factor responsible for yield increase in olives. To take into account this effect, an index of the percent of irrigated area was introduced (Quiroga \& Iglesias 2009). The models include autoregressive terms in order to correct the autocorrelation of the residuals and to capture the dynamics of the data. Finally, some impulse dummy variables (with a value of 1 in a selected year) have been added to the models in order to isolate the effects of some anomalous drought years.

Limitations of our approach arise from the simplicity of the empirical models and the quality of observed data. The use of statistical models for projections in a structural change context has often been questioned. Nevertheless, regression models are robust within the data range in which they are calibrated. Here, we have used $40 \mathrm{yr}$ of climate data, including a range of temperatures and precipitation extremes, to estimate the models. The data include a range of temperatures and precipitation extremes that vary more than the aver- age changes projected by the climatechange models, so the limitations in terms of the extent of the data are reduced and the models can be reliably extrapolated given that the projections are inside the range in which the regression models apply. We have incorporated autoregressive terms in order to capture the dynamics and non linear relationships of data.

A major challenge facing all agroclimate evaluations is to include both biophysical and socio-economic aspects in the methodology. Numerous studies have used agricultural simulation models to capture these complex interactions. Multiple regression models can also represent process-based yield responses to these environmental and management variables, providing the historical perspective. Although simple functions will never provide the detail possible with more complex models, the direct interpretation of the results by farmers and policymakers may be of great value to the risk management and decision-making process.

The specified models have the general form:

$$
\begin{aligned}
& \ln Y_{t}=\eta Y_{t-1}+\alpha_{0}+\alpha_{1 \mathrm{Mac}} \mathrm{Mac}_{t}+\alpha_{1 \mathrm{Fer}} \mathrm{Fer}_{t}+\alpha_{1 \mathrm{Irri}} \mathrm{Irri}_{t}+ \\
& \alpha_{2 i} \operatorname{Tav}_{i t}+\alpha_{3 i} \mathrm{Fr}_{i t}+\alpha_{4 i} \operatorname{Prec}_{i t}+\alpha_{5 i} \operatorname{Tmax}_{i t}+ \\
& \alpha_{6} \operatorname{Dr}_{t}+\beta_{t^{*}} \operatorname{Impt}_{t}^{*}+\varepsilon_{t}
\end{aligned}
$$

where the dependent variable $\left(Y_{t}\right)$ is the crop yield for a site in year $t$ and the explanatory variables are divided into 2 categories: management variables (Mac, Fer and Irri represent agricultural machinery, input agrochemicals and irrigation, respectively) and climate variables (Tav, Fr, Prec, Tmax, and Dr represent average temperature, number of days with temperature below zero, precipitation, maximum temperature and a drought index, respectively). $\alpha$ and $\beta$ are the estimated parameters, and Impt $_{t}^{*}$ is a dummy variable denoting an impulse effect on year $t^{*}$. The subscript $i$ on the climate variables refers to the month and 3 month periods ( $i=$ Jan, ..., Dec; SON, Sep-Nov; DJF, Dec-Feb; MAM, Mar-May; and JJA, Jun-Aug). Multicolinearity, heteroscedasticity and autocorrelation diagnosis of variables was considered. All estimated parameters $\left(\alpha_{1-12}, \beta\right.$ and $\left.\eta\right)$ were significant at the $95 \%$ level. A complete econometric treatment is described in Quiroga \& Iglesias (2009), Iglesias \& Quiroga (2007) and Iglesias et al. (2000).

The yield response model used ignored potential fertilisation effects of elevated atmospheric $\mathrm{CO}_{2}$ on crop yields when comparing different global production systems, following the approach of Lobell et al. (2008). The expected difference in $\mathrm{CO}_{2}$ concentration between 
Table 4. Representative sites and crops. $T_{\text {avg }}$ average temperature; $P_{\text {avg }}$ : average precipitation; $\times$ : crops and locations simulated

\begin{tabular}{|c|c|c|c|c|c|c|c|c|c|}
\hline \multirow[b]{3}{*}{ Burgos } & \multirow{2}{*}{\multicolumn{2}{|c|}{ Coordinates -}} & \multirow{2}{*}{$\begin{array}{l}\text { Altitude } \\
\text { (m) }\end{array}$} & \multirow{2}{*}{$\begin{array}{l}T_{\text {avg }} \\
\left({ }^{\circ} \mathrm{C}\right)\end{array}$} & \multirow{2}{*}{$\begin{array}{c}P_{\mathrm{avg}} \\
(\mathrm{mm})\end{array}$} & \multirow[b]{2}{*}{ Cereals } & \multicolumn{2}{|c|}{ - Simulated crops } & \multirow[b]{2}{*}{ Olives } \\
\hline & & & & & & & Citrus & Grapes & \\
\hline & $42.37^{\circ} \mathrm{N}$ & $3.63^{\circ} \mathrm{W}$ & 894 & 10.2 & 630 & $x$ & & & \\
\hline Logroño & $42.45^{\circ} \mathrm{N}$ & $2.33^{\circ} \mathrm{W}$ & 353 & 13.4 & 383 & $x$ & & $\times$ & $x$ \\
\hline Murcia & $38.00^{\circ} \mathrm{N}$ & $1.10^{\circ} \mathrm{W}$ & 0 & 17.6 & 305 & $x$ & $\times$ & $x$ & $x$ \\
\hline Cordoba & $37.85^{\circ} \mathrm{N}$ & $4.83^{\circ} \mathrm{W}$ & 92 & 17.9 & 674 & $x$ & $x$ & $x$ & $x$ \\
\hline
\end{tabular}

the 1960-2000 period and the 2080s for the A2 and B2 scenarios may result in a slight yield difference in wheat, which has a C3 photosynthetic pathway (Nicholls 1997, Long et al. 2005, 2006). Citrus, grapes and olives also have a C3 photosynthetic pathway, but their response to $\mathrm{CO}_{2}$ has not been tested. The $\mathrm{CO}_{2}$ effects vary considerably across crops and production conditions, and the response in field conditions with water and other input limitations may be negligible. Therefore, attempting to quantify them in a comparative study may result in the inclusion of an uncontrolled error. The exclusion of the direct $\mathrm{CO}_{2}$ effect should not affect relative uncertainty or the differences between different policy scenarios and crops.

The 4 study sites and 4 crops are representative of Mediterranean agriculture. Data on observed crop yields at province level were taken from MAPA (2004) for the selected crops and sites (Table 4). For each site, series of maximum and minimum temperatures, number of days per month with temperature below $0^{\circ} \mathrm{C}$, and precipitation for the 1959-2000 period were obtained from the National Meteorological Service (Spain). The typical Mediterranean region has small seasonal temperature differences and precipitation totals that decrease with decreasing latitude. In general, summer (June, July and August) precipitation is well below $100 \mathrm{~mm}$ and the coefficient of variation (CV) of precipitation varies from 21 to $55 \%$ over the entire crop cycle. This implies the need for supplemen- tary irrigation during part of the crop cycle in order to meet average water demand, avoid water shortage risk and obtain adequate production levels. These 4 sites show differences in seasonal temperature and the amount and distribution of precipitation, and are also characterised by different crop management practices and levels of production. Burgos represents the northern region of the plateau, where seasonal precipitation meets crop water demand for winter crops during the entire crop cycle. Logroño represents the milder northern region, which specialises in high-quality crops and, especially, grapes, which are irrigated during the early summer. Cordoba, located in Andalusia (southern Spain), is a highly productive area representative of the climate of the Mediterranean region. Murcia represents the southern Mediterranean coastal climate, where the frost-free period comprises almost the entire season, but irrigation is a necessity for almost all crops. Table 5 shows some examples of the statistical models that have been used. Estimated coefficients are illustrated in Quiroga \& Iglesias $(2009,2010)$ and Iglesias \& Quiroga (2007).

The statistical functions of yield response have been used to evaluate the effect of climate-change projections on future yield. The production changes due to climate change are calculated considering the following relationship:

$\mathrm{d} \ln Y_{t}=\frac{1}{(1-\eta B)}\left[\alpha_{2 i} \mathrm{dTav}_{i t}+\alpha_{4 i} \mathrm{dPrec}_{i t}+\alpha_{5 i} \mathrm{dTmax}_{i t}\right]$

Table 5. Examples of the statistical models used to calculate the changes in production of cereals, olives and citrus (see Section 2.3 for variable definitions)

\begin{tabular}{|c|c|c|}
\hline Crop (Site) & Regression model & Source \\
\hline Cereals (Burgos) & $\begin{array}{l}\ln Y_{t}=0.2891 \ln Y_{t-1}+0.0033 \mathrm{Mac}_{t}+0.0645 \mathrm{Tav}_{\mathrm{DJF}_{t}}-0.0404 \mathrm{Fr}_{\mathrm{MAY}_{t}}- \\
-0.0106 \mathrm{Fr}_{\mathrm{SON}_{t}}-0.017 \text { Precip }_{\mathrm{DEC}_{t}}-0.0262 \operatorname{Tmax}_{\mathrm{MAY}_{t}}\end{array}$ & Iglesias \& Quiroga (2007) \\
\hline Olives (Cordoba) & $\begin{array}{l}\ln Y_{t}=0.0004 \mathrm{Fer}_{t}+0.1483 \mathrm{Irri}_{t}-0.0766 \mathrm{Fr}_{\mathrm{NOV} t}-0.0091 \mathrm{Fr}_{\mathrm{DJF} t}+ \\
+0.0030 \mathrm{Prec}_{\mathrm{APR} t}+0.0133 \mathrm{Prec}_{\mathrm{AUG} t}-1.2606 \mathrm{Tmax}_{\mathrm{MAY} t} \operatorname{Impt} 65- \\
-0.7086 \mathrm{Imp} 95\end{array}$ & Quiroga \& Iglesias (2009) \\
\hline Citrus (Murcia) & $\begin{array}{l}\ln Y_{t}=0.0482 \mathrm{Tav}_{\mathrm{DJF} t}-1.1883 \mathrm{Fr}_{\mathrm{APR} t}-0.0337 \mathrm{Tmax}_{\mathrm{OCT} t}-0.1088 \mathrm{Dr}- \\
-0.3102 \mathrm{Impt} 56_{\mathrm{DJF} t}-0.4570 \mathrm{Impt} 63-0.3712 \mathrm{Impt} 94\end{array}$ & Quiroga \& Iglesias (2010) \\
\hline
\end{tabular}


where $B$ is the back shift operator ( $B$-operator), which transforms an observation of a time series to the previous observation. The climate variations applied were those projected for each of the climate-change scenarios considered.

\subsection{Risk level}

The probability distribution of production changes for the 2080s for each crop and location was estimated using the Monte Carlo method. Monte Carlo simulations are widely used to derive large size samples from short time series of observational data (Robert \& Casella 2004). The Monte Carlo method is used in agriculture to characterise statistical properties of crop yield prices, as well as crop yield as a response to rainfall or other inputs. Here we applied Monte Carlo methods to derive probability distribution functions of yield risk levels. The approach consists of generating a synthetic series of yield variables using the Monte Carlo method and Latin hypercube sampling (Just \& Weninger 1999, Atwood et al. 2003)

Monte Carlo methods are an important component of uncertainty and probabilistic risk assessments because they allow for the generation of random samples of statistical distributions (Robert \& Casella 2004). Monte Carlo methods simulate the behaviour of a system in a nondeterministic manner (stochastic) by using random numbers as opposed to deterministic algorithms. The Latin hypercube technique is a variation of the simpler Monte Carlo technique, and employs a constrained sampling scheme used when the dependent variable $(Y)$ is a function of several other variables $\left(X_{1}, X_{2}, \ldots, X_{k}\right)$, as is the case of crop yield.

\subsection{Impact to risk index}

A standardised impact to risk index (SIR) is proposed to quantify the magnitude and likelihood of having an impact in each location and crop. This diagnostic probabilistic measure of uncertainty is useful for proposing the most appropriate adaptation strategy in each case. The SIR was computed as the ratio between the risk, measured as the average probabilistic impact, and the standardised kurtosis of the impact distribution. Kurtosis is a measure of the relative concentration flatness or peakedness of the probability distribution of a real-valued random variable. Distributions with higher kurtosis have fatter tails or more extreme values, as opposed to distributions with lower kurtosis, which have fatter middles or fewer extremes. Kurtosis values are always positive because they are defined as: $\mu_{4} / \sigma^{4}$, where $\mu_{4}$ is the fourth moment of the mean and $\sigma$ is the standard deviation. Therefore, the sign of the SIR is derived from the sign of the impacts. Negative values of SIR indicate negative impacts and positive values of SIR indicate positive impacts. Because the SIR index is standardised, it is a normal distribution, $N(0,1)$ and $90 \%$ of the values are between -2 and +2 . The SIR index weighs the impacts and their associated likelihood. A positive or negative impact that has associated large uncertainty is more difficult to address with adaptation measures and, therefore, the 'real' risk will be even more negative. Table 6 provides an interpretation of the values of the SIR index.

\section{RESULTS AND DISCUSSION}

\subsection{Uncertainty derived from the choice of scenarios}

In Mediterranean agriculture, precipitation determines a large proportion of the observed and projected changes in crop yield. Therefore, this variable is of key importance for estimating impacts and their likelihood. Fronzek \& Carter (2007) hint at a systematic difference between downscaling only the temperature output of the global climate models and not the precipitation output. Therefore, in order to broaden the possible choice of climate and emissions models, we have not included downscaled scenarios in our analysis. Projections of annual mean changes in temperature and annual changes in precipitation from the 16 scenarios are summarised in Fig. 2. Temperature increased by 1.5 to $5.5^{\circ} \mathrm{C}$. Maximum distance among temperatures was higher among the SRES scenarios than across different GCMs. Therefore, in general, the socioeconomic conditions, as determined by the SRES scenarios, had a higher impact on temperature changes than the climate models. However, the opposite effect was observed in the precipitation changes, which varied much more across different climate models. In all cases, the temperature increase of the A scenarios was larger than that of the B scenarios, and the A1 is larger

Table 6. Interpretation of the values of the standardised impact to risk (SIR) index

\begin{tabular}{|ll|}
\hline SIR value & \multicolumn{1}{c|}{ Interpretation } \\
\hline+2 and more & Positive impact (opportunity), highly unlikely \\
+0.5 and more & Positive impact (opportunity), likely to occur \\
-0.5 to 0.5 & Likelihood of little or no deviation from current state \\
-0.5 and less & Negative impact (risk), likely to occur \\
-2 and less & Negative impact (risk), highly unlikely \\
\hline
\end{tabular}




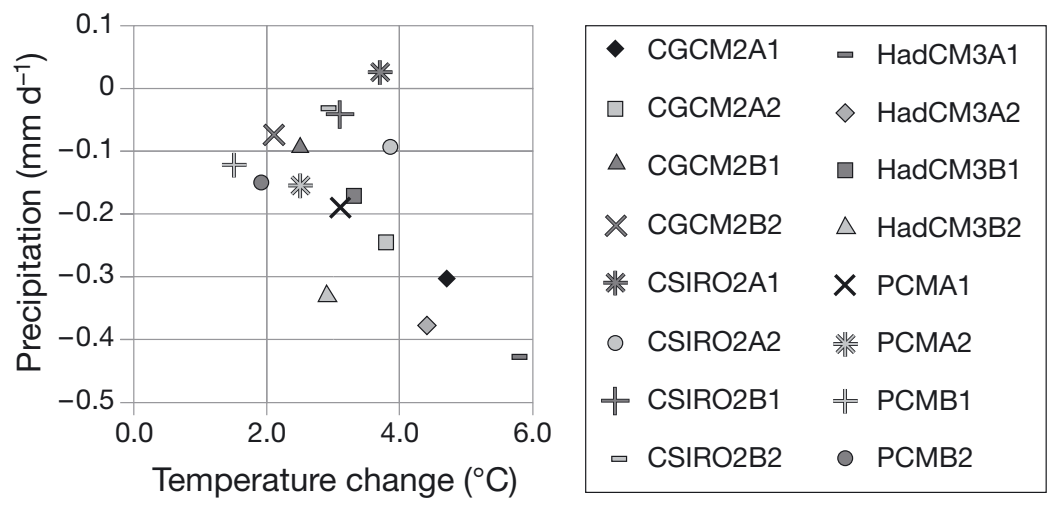

Fig. 2. Changes in annual average temperature and total annual precipitation by 2071-2100 relative to 1961-1990 averaged over Spain from 4 global climate models under the A1, A2, B1 and B2 scenarios. Data source: Tyndall Centre (Mitchell et al. 2004)
2100) climate was then added to the observed temperature and precipitation time series (delta change approach). Therefore, the scenario climate variability remains the same as in the observational record. Some studies use a weather generator to derive changes in variability (Semenov 2008, Semenov \& Stratonovitch 2010) or apply the individual year output of GCMs to the observed baseline period mean (Fronzek \& Carter 2007). Here we analysed variability of agricultural output by generating a probabilistic distribution of extremes using a Monte Carlo simulation (Section 3.3). than the A2, except in the output from CSIRO. All scenarios project drier than current conditions for the region; precipitation decreased by 10 to $60 \%$ in all cases except in the CSIRO A1 output, where annual precipitation increased by $<5 \%$ of current precipitation levels.

In all the scenarios reported here, the absolute difference between modeled (1961-1990) and future (2071-

\subsection{Uncertainty of the agricultural system}

Median projections for Mediterranean crops exhibit a very wide response to climate-change scenario and location (Fig. 3). Whereas cereal production may be at cosiderable risk in southern locations, grape yields may increase in some key producing regions. Because these results are derived from statistical models of
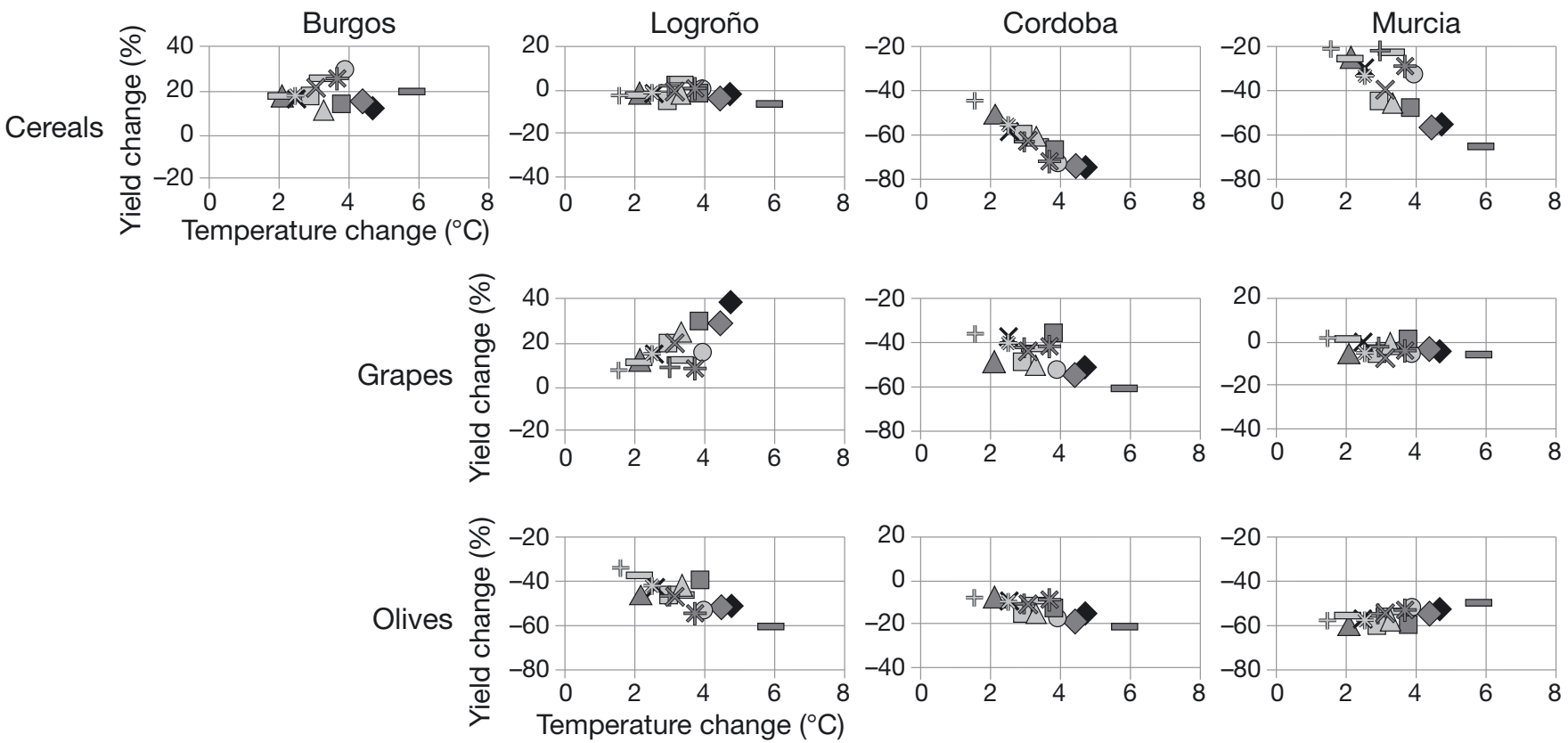

Fig. 3. Crop yield changes under the 16 scenarios for the period 2071-2100 compared to baseline, plotted against the temperature change in the corresponding scenario. Symbols as in Fig. 2. Note differences in $y$-axis scales
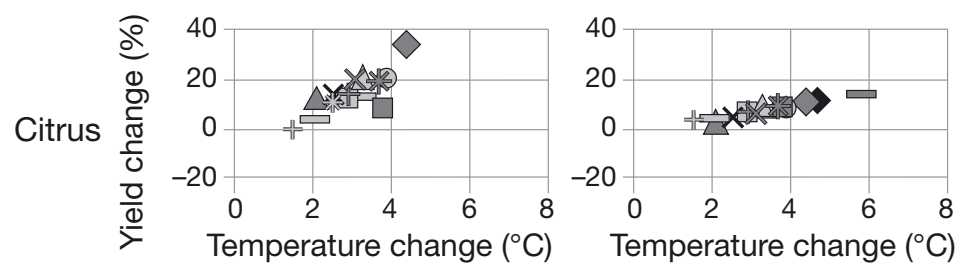


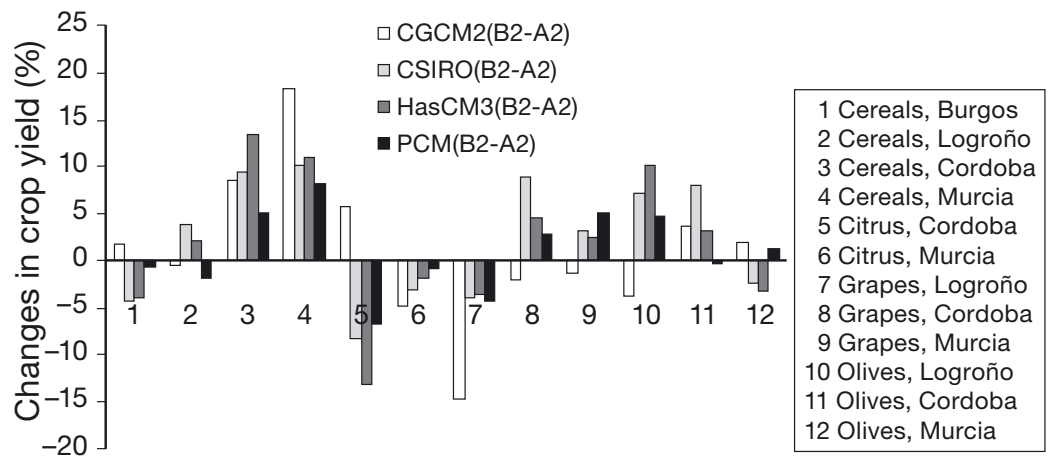

Fig. 4. Effect of mitigation action estimated as changes in productivity between the A2 and B2 scenarios for each climate model

yield response, it is likely that they underestimate crop yield variability at the farmer level (Gorski \& Gorska 2003). In general, northern and southern locations show contrasting results, as has been previously reported (Olesen \& Bindi 2002, Fronzek \& Carter 2007). In the present study, we evaluated the local and crop-specific responses. Projected future climate may result in an opportunity for cereal production in the northern sites, but may be very negatively affected in southern sites, where supplemental irrigation will probably be necessary under warmer and dryer conditions. Citrus is always irrigated in Spain and, therefore, a temperature increase of up to $5^{\circ} \mathrm{C}$ does not have a significant effect on crop productivity (Medina et al. 2002). This result has to be interpreted with care because a higher evapotranspiration rate implies a substantial increase in the amount of water needed for irrigation. In areas where citrus crops are grown, the competition for water is already an acute problem.

Of the crops analysed, grapes show the most varied yield response depending on local conditions. As in the case of other widely irrigated crops in Murcia, climate change does not have a substantial impact in this location. By contrast, the response in Cordoba is extremely negative, whereas in Logroño, climate change may result in increased production for grape cultivation. Finally, olive production is clearly at risk at the marginal production locations (Logroño and Murcia), whereas climate change may not be a large threat in the main olive production region of the world (Andalusia), represented in the present study by Cordoba.

Fig. 4 shows the effect of the socio-economic scenario assumptions on the implications of crop productivity. Here we calculated the value of crop yield under the A2 scenario, which is considered as the businessas-usual future projection, with respect to the B2 scenario, which is considered a mitigation scenario with projected impacts that are unavoidable, even if reduction of greenhouse gas emissions are implemented. This difference can therefore be interpreted as an approximate indicator of the effect of mitigation action, or the difference between the potential economic effect of inaction and the so-called committed climate change. Potential benefits or reductions in crop productivity, from taking action to reduce greenhouse gas emissions, are crop and location specific (Fig. 4).

Table 7. Descriptive statistics of the yield derived from Monte Carlo simulations for the 4 crops and locations

\begin{tabular}{|c|c|c|c|c|c|c|c|c|}
\hline Crop & Min. & Max. & Mean & $\mathrm{SD}$ & Deviation & Variance & Skewness & Kurtosis \\
\hline \multicolumn{9}{|l|}{ Cereals } \\
\hline Burgos & 0.07050 & 0.63039 & 0.18786 & 0.05288 & 0.00280 & 115.045 & 552.180 & 0.07050 \\
\hline Logroño & -0.09898 & 0.09010 & -0.01353 & 0.02474 & 0.00061 & 0.15918 & 303.406 & -0.09898 \\
\hline Cordoba & -0.85910 & -0.09528 & -0.64007 & 0.11516 & 0.01326 & 0.62996 & 323.623 & -0.85910 \\
\hline Murcia & -0.79648 & 0.96690 & -0.35982 & 0.17818 & 0.03175 & 113.662 & 536.395 & -0.79648 \\
\hline \multicolumn{9}{|l|}{ Grapes } \\
\hline Burgos & - & - & - & - & - & - & - & - \\
\hline Logroño & -0.04252 & 0.96689 & 0.19491 & 0.09446 & 0.00892 & 114.851 & 549.994 & -0.04252 \\
\hline Cordoba & -0.66613 & 0.49367 & -0.43926 & 0.09625 & 0.00926 & 118.162 & 592.001 & -0.66613 \\
\hline Murcia & -0.09491 & 0.21838 & -0.02525 & 0.02986 & 0.00089 & 114.662 & 547.802 & -0.09491 \\
\hline \multicolumn{9}{|l|}{ Citrus } \\
\hline Burgos & - & - & - & - & - & - & - & - \\
\hline Logroño & - & - & - & - & - & - & - & - \\
\hline Cordoba & -0.47527 & 0.98454 & 0.19664 & 0.16878 & 0.02849 & 0.00348 & 302.124 & -0.47527 \\
\hline Murcia & -0.04624 & 0.18794 & 0.07179 & 0.03095 & 0.00096 & -0.00025 & 299.436 & -0.04624 \\
\hline \multicolumn{9}{|l|}{ Olives } \\
\hline Burgos & - & - & - & - & - & - & - & - \\
\hline Logroño & -0.65114 & 0.25349 & -0.45989 & 0.08592 & 0.00738 & 114.982 & 551.116 & -0.65114 \\
\hline Cordoba & -0.24789 & 0.26682 & -0.11869 & 0.05597 & 0.00313 & 113.018 & 529.370 & -0.24789 \\
\hline Murcia & -0.65479 & -0.40810 & -0.55977 & 0.03105 & 0.00096 & 0.39656 & 325.482 & -0.65479 \\
\hline
\end{tabular}




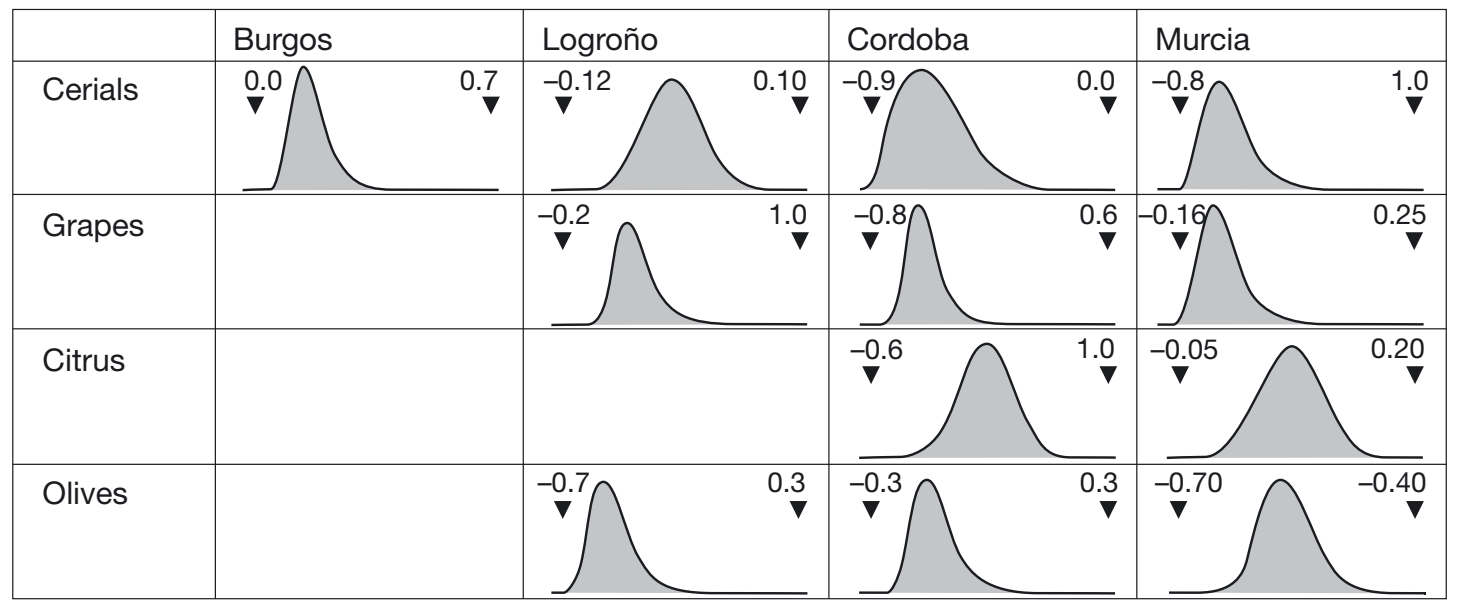

Fig. 5. Statistical distribution of yield derived from Monte Carlo simulations for the 4 crops and locations. The values of the distribution functions shown are the confidence limits of the $95 \%$ confidence interval of the standardised crop yield distribution function

\subsection{Risk level}

We used Monte Carlo simulations to derive random samples (10000 values) of statistical distributions of crop yield to analyse the distribution of probabilities in order to obtain a certain yield (the risk level) (Table 7, Fig. 5). Our results show large differences in impact levels on yield distribution functions across sites and crops. The variance is useful as a non-dimensional indicator of variability in general. Logroño has a low variance, whereas Córdoba has the highest. However, the variance is not a complete indicator of variability in risk analyses, and it is necessary to analyse other statistical parameters. In general, the skewness coefficients do not indicate a large probability of low yield, since only values below -1 indicate very negatively skewed data. For grapes in all locations there was a higher probability of obtaining yields greater than the mean, as indicated by the skewness coefficients above +1 . Kurtosis is a parameter that describes the shape of the probability density function of a random variable. The kurtosis coefficients of the data presented in Table 7 and Fig. 5 are $>3$, indicating leptokurtic distributions, meaning that the probability distribution functions of the yields are simultaneously 'peaked' and have 'fat tails.' High kurtosis values indicate that the distribution of impacts is closely

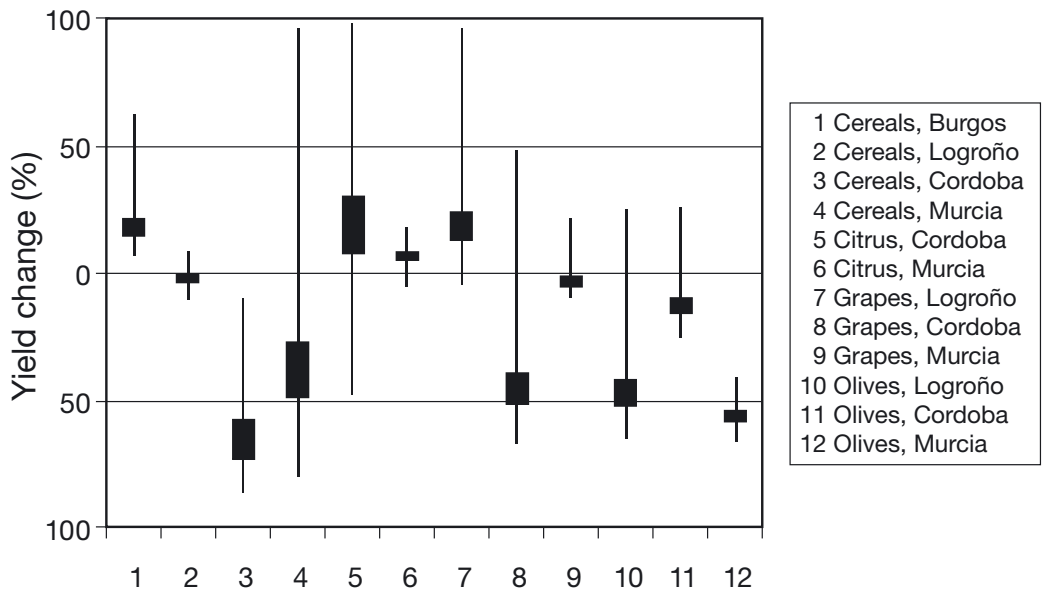

Fig. 6. Summary of projected yield variation derived from Monte Carlo simulations. Boxes form the 25 th to the 75 th percentiles, and vertical lines extend from the maximum to minimum

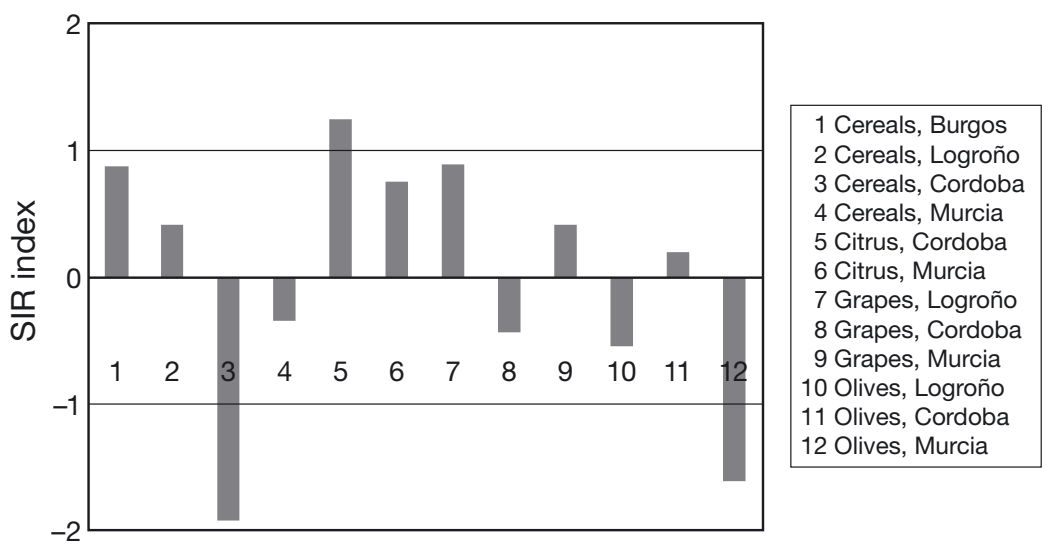

Fig. 7. Standardised impact to risk index (SIR) projected for a combination of locations and crops in the Mediterranean region 
centred around the mean; we may interpret this to mean that the projected impact is more certain, since we have considered a high enough number of scenarios. The yield variation is considerably different for each site and crop (Fig. 6); olives present the smallest variation across sites, which can be explained by the fact that olives are well adapted to the variable Mediterranean climate.

We have developed an integrating index that relates impacts to likelihood. The SIR index shown in Fig. 7 is calculated as the ratio between the impact and the standardised kurtosis of the impact distribution. We propose some thresholds of the SIR value to support decisions on the adaptation priorities. The results provide information about the choice of crop to minimise risk, addressing the risk at the levels of farming system and location. This can also guide policy decisions at different levels of government. On the basis of a broader analysis that includes more locations and crops, some thresholds of the SIR value to support decisions on adaptation priorities could be developed.

\section{CONCLUSIONS}

To some extent, plants and crops will be able to naturally adapt to a changed climate. However, this is likely to be insufficient (Stalker 2006), and human intervention will continue to have an important role in facilitating adaptation of crops. This will occur through research in and support of changes in farming practices, irrigation, providing access to inputs, and the genetic improvement of crops using traditional breeding methods and biotechnology. (Cheikh et al. 2000, FAO 2004). In order to decide on the appropriate investments and policies aimed at improving agricultural adaptation to climate change, it is important to be aware of the probable impacts and associated uncertainty, as well as the crops and locations that are likely to be affected.

Scientific uncertainty and institutions' perception of this are key factors determining investments and policies aimed at improving agricultural adaptation to climate change (Lobell et al. 2008). There is considerable uncertainty surrounding future impacts of climate on crops and yields. This uncertainty is derived from climate models (and the underlying assumption of the driving forces), crop type, as well as location, and is increased during the conversion of emissions values to climate change, from climate change to possible impacts and, finally, from these driving forces to formulating adaptation and mitigation policies (Gupta et al. 2003). Furthermore, the complexity of the socioeconomic system and historical and biophysical dynamics that underpin the agricultural sector condi- tion the possible type of actions and responses and add an additional layer of complexity (Ziervogel \& Zermoglio 2009).

Apart from taking into account yield differences for 4 crops (cereals, citrus, grapes and olive) and locations (Burgos, Logroño, Cordoba and Murcia), we have also based our projections on 16 climate models from 4 different sources (CGCM, CSIRO, HadCM and PCM) and using 4 SRES scenarios (A1, A2, B1 and B2). The results of our analyses agree with the agronomic knowledge of crop responses to climate (Porter \& Semenov 2005), but the risk ranking of the regions is not intuitive when only considering the variables in isolation. For example, Murcia is a very dry region and the common perception is that the risk to crop production is higher. However, although cereals and olives are projected to experience considerable decreases in yields, citrus and grapes, which are both irrigated in the region, are not. None of the crops offer a clear advantage over others in all of the regions; regional adverse impacts are, as can be expected, more acute in the southern study sites (Cordoba and Murcia) than in more northern location (Burgos and Logroño). This supports the argument that any policies or adaptation response needs to be location-specific and, often, cropspecific in order to adequately consider and address the likely climate impacts in the region as well as the specific management and socio-economic conditions (i.e. irrigation) of the location.

The risk level that was analysed as part of this study may provide some policy guidance, regardless of the impact and its severity. Considering the distribution of the risk level, we can deduce the likelihood of the impact occurring and, thereby, target policy actions to address the particular level and certainty of the impact. For example, olives in Murcia are expected to decrease yields substantially, and the likelihood of this occurring at the projected level is very high, given the small variation between the 5th and 95th percentiles. The derived SIR index supports making informed decisions by providing an intuitive and comparable measure of the impact likelihood. Similarly, we can see that the level of impact overall is greatest for cereals in Cordoba and that the likelihood of this occurring is high. Ideally, this should trigger a policy or stakeholder response in order to reduce the negative impacts likely to be experienced by farmers of these crops in the studied regions.

Over the next few decades, a central goal of agricultural and policy decisions will be to decrease the risk associated with a changing climate. Future policy actions in the Mediterranean need to be focused on helping farmers to adopt strategies that are in compliance with current and developing legislation and programs, especially in view of the continued reform of 
the Common Agricultural Policy of the European Union and the implementation of other policies such as the EU Water Framework Directive. Fundamental to this aim is the development of the ability to quantify climate risks associated with different geographical locations as well as different crops. Evaluating the uncertainty and risk level and analysing the likelihood of a particular event occurring through the use of indicators, such as the SIR index, might serve to guide policymakers and stakeholders as they face adverse climate impacts. Finally, scientific advances of climate change projections based on new scenarios (Moss et al. 2010) will provide a clearer understanding of uncertainties in the field of climate change research.

Acknowledgements. This research has been supported by the European Commission CIRCE project and the ARCO project of the Spanish Ministry of Environment, Rural, and Marine Affairs.

\section{LITERATURE CITED}

Atwood J, Shaik S, Watts M (2003) Are crop yields normally distributed? A re-examination. Am J Agric Econ 85: 888-901

Brooks N, Adger WN, Kelly PM (2005) The determinants of vulnerability and adaptive capacity at the national level and implications for adaptation. Glob Environ Change 15: 151-163

Burton I, Lim B (2005) Achieving adequate adaptation in agriculture. Clim Change 70:191-200

Carter TR, Porter TR, Parry ML (1991) Climatic warming and crop potential in Europe: prospects and uncertainties. Glob Environ Change 1:291-312

Chavas J, Kim K, Lauer J, Klemme R, Bland W (2001) An economic analysis of corn yield, corn profitability and risk at the edge of the Corn Belt. J Agric Res Econ 26:230-247

Cheikh N, Miller PW, Kishore G (2000) Role of biotechnology in crop productivity in a changing environment. In: Reddy KR, Hodges HF (ed) Global change and crop productivity. CABI Publishing, New York, p 425-436

Ciscar JC, Iglesias A, Feyen L, Goodess CM and others (2009) Climate change impacts in Europe. Final report of the PESETA research project. EUR 24093 EN. JRC Scientific and Technical Reports, Seville

Commission of the European Communities (2009) Adapting to climate change: towards a European framework for action. COM(2009) 147 final. Commission of the European Communities, Brussels

Dixon BL, Hollinger SE, Garcia P, Tirapattur V (1994) Estimating corn yield response models to predict impacts of climate change. J Agric Res Econ 19:58-68

European Environment Agency (2008) Impacts of climate change in Europe: an indicator based report. EEA Report 4, 2008. EEA-European Communities, Copenhagen, available at www.eea.europa.eu/publications/eea_report_2008_4

FAO (Food and Agriculture Organisation of the United Nations) (2004) Agricultural biotechnology: meeting the needs of the poor. The State of Food and Agriculture 2003-2004. FAO, Rome

FAO (Food and Agriculture Organisation of the United Nations) (2010) FAOSTAT. FAO, Rome, available at http:// faostat.fao.org
Ferreyra RA, Podestá GP, Messina CD, Lestón D, Dardanelli J, Guevara E, Meira S (2001) A linked-modeling framework to estimate maize production risk associated with ENSO-related climate variability in Argentina. Agric For Meteorol 107:177-192

Fronzek S, Carter T (2007) Assessing uncertainties in climate change impacts on resource potential for Europe based on projections from RCMs and GCMs. Clim Change 81: $357-371$

Giorgi F, Lionello P (2008) Climate change projections for the Mediterranean region. Glob Planet Change 63:90-104

Gorski T, Gorska K (2003) The effects of scale on crop yield variability. Agric Syst 78:425-434

Gupta J, Olzthoorn X, Rotemberg E (2003) The role of scientific uncertainty in compliance with the Kyoto protocol to the climate change convention. Environ Sci Policy 6: $475-486$

> Howden SM, Soussana JF, Tubiello FN, Chhetri N, Dunlop M, Meinke H (2007) Adapting agriculture to climate change. Proc Natl Acad Sci USA 104:19691-19696

Hulme M, Barrow E, Arnell N, Harrison P, Johns T, Downing T (1999) Relative impacts of human-induced climate change and natural climate variability. Nature 397:688-691

Iglesias A, Quiroga S (2007) Measuring the risk of climate variability to cereal production at five sites in Spain. Clim Res 34:47-57

Iglesias A, Rosenzweig C, Pereira D (2000) Agricultural impacts of climate in Spain: developing tools for a spatial analysis. Glob Environ Change 10:69-80

Iglesias A, Garrote L, Flores F, Moneo M (2007) Challenges to manage the risk of water scarcity and climate change in the Mediterranean. Water Resour Manage 21:227-288

IPCC (2000) Special report on emissions scenarios: a special report of Working Group III of the Intergovernmental Panel on Climate Change [Nakicenovic N, Swart R (eds)]. Cambridge University Press, Cambridge

IPCC (2007) Climate change 2007: impacts, adaptation and vulnerability. In: Parry ML, Canziani OF, Palutikof JP, van der Linden PJ, Hanson CE (eds) Contribution of Working Group II to the Fourth Assessment Report of the Intergovernmental Panel on Climate Change. Cambridge University Press, Cambridge

Just RE, Weninger Q (1999) Are crop yields normally distributed? Am J Agric Econ 81:287-304

> Lobell DB, Ortiz-Monasterio JI, Falcon WP (2007) Yield uncertainty at the field scale evaluated with multi-year satellite data. Agric Syst 92:76-90

> Lobell DB, Burke MB, Tebaldi C, Mastrandrea MD, Falcon WP, Naylor RL (2008) Prioritizing climate change adaptation needs for food security in 2030. Science 319:607-610

Long SP, Ainsworth EA, Leakey ADB, Morgan PB (2005) Global food insecurity. Treatment of major food crops with elevated carbon dioxide and ozone under large-scale fully open-air conditions suggests models may seriously overestimate future yields. Philos Trans R Soc Lond B 360: 2011-2020

> Long SP, Ainsworth EA, Leakey ADB, Nsberger J, Ort DR (2006) Food for thought: lower-than-expected crop yield stimulation with rising $\mathrm{CO}_{2}$ concentrations. Science 312: 1918-1921

> Luo H, Skees JR, Marchant MA (1994) Weather information and the potential for the inter-temporal adverse selection in crop insurance. Rev Agric Econ 16:441-451

Ministerio de Agricultura, Pesca y Alimentación (MAPA) (2004) Anuarios de Estadística Agroalimentaria, years: 1940 to 2000. Ministry of Agriculture, Statistical Division, Madrid 
Medina CL, Souza RP, Machado EC, Ribeiro RL, Silva JAB (2002) Photosynthetic response of citrus grown under reflective aluminized polypropylene shading nets. Sci Hortic 96:115-125

Mitchell TD, Carter TR, Jones PD, Hulme M, New M (2004) A comprehensive set of high-resolution grids of monthly climate for Europe and the globe: the observed record (19012000) and 16 scenarios (2001-2100). Tyndall Centre for Climate Change Research, Working Paper 55. Available online at IPCC DDC www.ipcc-data.org/docs/tyndall_ working_papers_wp55.pdf

Moss RH, Edmonds JA, Hibbard KA, Manning MR and others (2010) The next generation of scenarios for climate change research and assessment. Nature 463:747-756

Nicholls N (1997) Increased Australian wheat yield due to recent climate trends. Nature 387:484-485

Olesen JO, Bindi M (2002) Consequences of climate change for European agricultural productivity, land use and policy. Eur J Agron 16:239-262

Parry MA, Rosenzweig C, Iglesias A, Livermore M, Fischer G (2004) Effects of climate change on global food production under SRES emissions and socio-economic scenarios. Glob Environ Change 14:53-67

Porter JR, Semenov MA (2005) Crop responses to climatic variation. Philos Trans R Soc B 360:2021-2035

Quiroga S, Iglesias A (2009) A comparison of the climate risks of cereal, citrus, grapevine and olive production in Spain.

Submitted: March 15, 2010; Accepted: August 5, 2010
Agric Syst 101:91-100

Quiroga S, Iglesias A (2010) A comparison of the climate marginal productivity on representative crop yields in Spain. Princip: Estud Econ Política 16:55-70

Robert CP, Casella G (2004) Monte Carlo statistical methods, 2nd edn. Springer-Verlag, New York

Rosenzweig C, Iglesias A, Fischer G, Liu Y, Baethgen W, Jones JW (1999) Wheat yield functions for analysis of land-use change in China. Environ Model Assess 4:128-132

Saarikko RA, Carter TR (1996) Estimating the development and regional thermal suitability of spring wheat in Finland under climatic warming. Clim Res 7:243-252

Semenov MA (2008) Simulation of extreme weather events by a stochastic weather generator. Clim Res 35:203-212

Semenov MA, Stratonovitch P (2010) Use of multi-model ensembles from global climate models for assessment of climate change impacts. Clim Res 41:1-14

Stalker P (2006) Technologies for adaptation to climate change. UNFCCC Climate Change Secretariat, Bonn, available at http://unfccc.int/resource/docs/publications/ tech_for_adaptation_06.pdf

Stanger TF, Lauer JG, Chavas JP (2008) The profitability and risk of long-term cropping systems featuring different rotations and nitrogen rates. Agron J 100:105-113

> Ziervogel G, Zermoglio F (2009) Climate change scenarios and the development of adaptation strategies in Africa: challenges and opportunities. Clim Res 40:133-146

Proofs received from author(s): September 24, 2010 